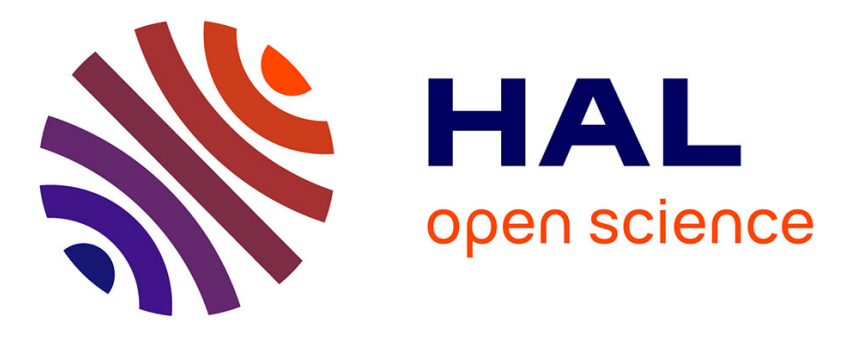

\title{
Preparation of a Key Tetraene Precursor for the Synthesis of Long Acenes
}

Gaspard Levet, Nguyen Khanh Hung, Michal Šámal, Jiří Rybáček, Ivana Císařová, Andrej Jancarik, André Gourdon

\section{- To cite this version:}

Gaspard Levet, Nguyen Khanh Hung, Michal Šámal, Jiří Rybáček, Ivana Císařová, et al.. Preparation of a Key Tetraene Precursor for the Synthesis of Long Acenes. European Journal of Organic Chemistry, inPress, 10.1002/ejoc.201901868. hal-02492893

\section{HAL Id: hal-02492893 \\ https://hal.science/hal-02492893}

Submitted on 27 Feb 2020

HAL is a multi-disciplinary open access archive for the deposit and dissemination of scientific research documents, whether they are published or not. The documents may come from teaching and research institutions in France or abroad, or from public or private research centers.
L'archive ouverte pluridisciplinaire HAL, est destinée au dépôt et à la diffusion de documents scientifiques de niveau recherche, publiés ou non, émanant des établissements d'enseignement et de recherche français ou étrangers, des laboratoires publics ou privés. 


\title{
Preparation of a key tetraene precursor for the synthesis of long acenes
}

Gaspard Levet,[a] Nguyen Khanh Hung,[a] Michal Šámal,[b] Jiř́ Rybáček,[b] Ivana Cisařová,[b] Andrej Jancarik*[a,b] and André Gourdon*[a]

\begin{abstract}
The tetraene 7,7-dimethoxy-2,3,5,6-tetramethylenebicyclo[2.2.1]heptane is a key compound for the preparation of a large variety of acenes protected by a carbonyl bridge. We report here a medium scale preparation in seven steps of this valuable starting material. Diels-Alder addition between 6,6-dimethyl fulvene and maleic anhydride, followed by carboxylation, ozonolysis of the double bond, reduction of the four ester group, then chlorination of the alcohol groups and dehydrochlorination give the target compound in $17 \%$ overall yield.
\end{abstract}

\section{Introduction}

Acenes, molecules comprising linearly fused benzene rings, have attracted a lot of interest for a long time and have also experienced a renewed interest[1,2] in the past decade for potential applications in molecular electronics,[3,4] spintronics[5] and plasmonics.[6]

However, the preparation of acenes longer than pentacene faces two main difficulties. First, the extension of the planar aromatic cores increases the intermolecular $\pi-\pi$ interactions, leading to less and less soluble compounds. Second, the reduction of the HOMO-LUMO gap increases the chemical reactivity towards oxidation and favours dimerization reaction even at very low concentration. To avoid these difficulties, long acenes have been studied under very high dilution conditions, on surfaces in UHV at liquid helium temperature or in cold matrices. In both types of experiments, stable and soluble precursors (epoxides, diketone or partially hydrogenated acenes) are prepared in solution and then, respectively, sublimated in UHV or dissolved in solvents which are then frozen to minimize the diffusion. The last reaction step yielding the acenes is done in situ thermally,[6-13] by tip-induced reactions,[7] or optically at low temperature.[15-21] Indeed these experiments are limited to minute amounts of compounds so that the preparation of long acenes as a material for organic thin-film transistors for instance is still a challenge. So far, the only long unsubstituted acenes prepared on macroscopic scale have been hexacene, benzohexacene and heptacene by thermal cheletropic decarbonylation of a monoketone precursor,[22,23] and heptacene by thermal cleavage of diheptacenes in the solid state at $300^{\circ} \mathrm{C}$.[24]

In order to overcome this limitation and to find a general practical route to many long acenes, we have recently investigated the use of the tetraene (7,7-dimethoxy-2,3,5,6tetramethylenebicyclo[2.2.1]heptane) $\mathbf{1}$ (scheme 1) as a key and valuable compound to access symmetrical or asymmetrical acenes.[23] The concept is the following one: 


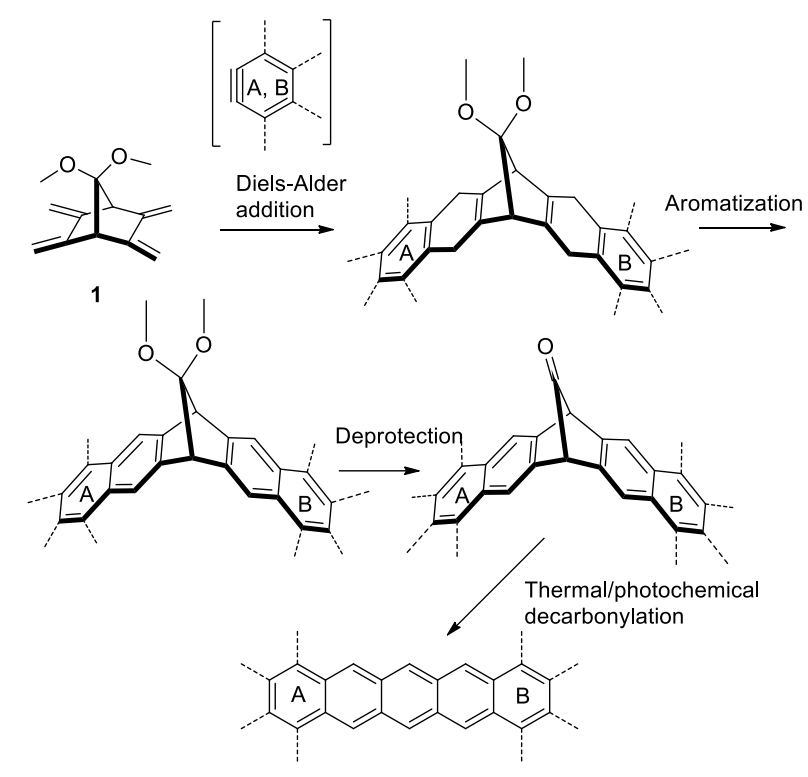

Scheme 1. Preparation of symmetrical $(A=B)$ and non-symmetrical $(A \neq B)$ acenes by cheletropic decarbonylation of $\mathrm{CO}$ bridged precursors.

Diels-Alder reaction of aryne(s) with the diene parts of the tetraene $\mathbf{1}$ gives, after aromatization by DDQ, a non-planar acene bridged by a dimethyl ketal. The non-planarity of the molecule reduces $\pi-\pi$ intermolecular stacking and provides some solubility whereas the bridge breaks the electronic delocalisation which reduces the chemical reactivity. Deprotection of the ketal gives a stable non-planar carbonyl bridged compound. The final step is a cheletropic thermal or photochemical decarbonylation, not in solution but in the solid or vapour phase. Photodecarbonylation can also be done in solid matrices at low temperature. Such final step is quantitative, without any non-gaseous by-product and can be used to prepare high-quality acenes for opto-electronic devices.[4] Our route allows the preparation of symmetrical or non-symmetrical acenes and could give an access to very long acenes by multiple Diels-Alder reactions.

In order to explore the synthetic potential of this promising starting material for the preparation of long acenes, we have reinvestigated and completed the synthesis of $\mathbf{1}$, previously described in parts in small scale and only for endo-endo isomers by Roth in 1991,[25] but here at larger scales (tens of grams). Therefore, we present here procedures minimizing separations by chromatography and relying on recrystallizations or simple washings on short plugs of silica gel, eventually at the expense of preparative yields.

\section{Results and Discussion}

The general synthetic route (scheme 2) follows in large parts the one described by Roth[25], but at larger scale with some experimental differences that will be explained below. 
$\mathrm{E}: \mathrm{CO}_{2} \mathrm{Me}$
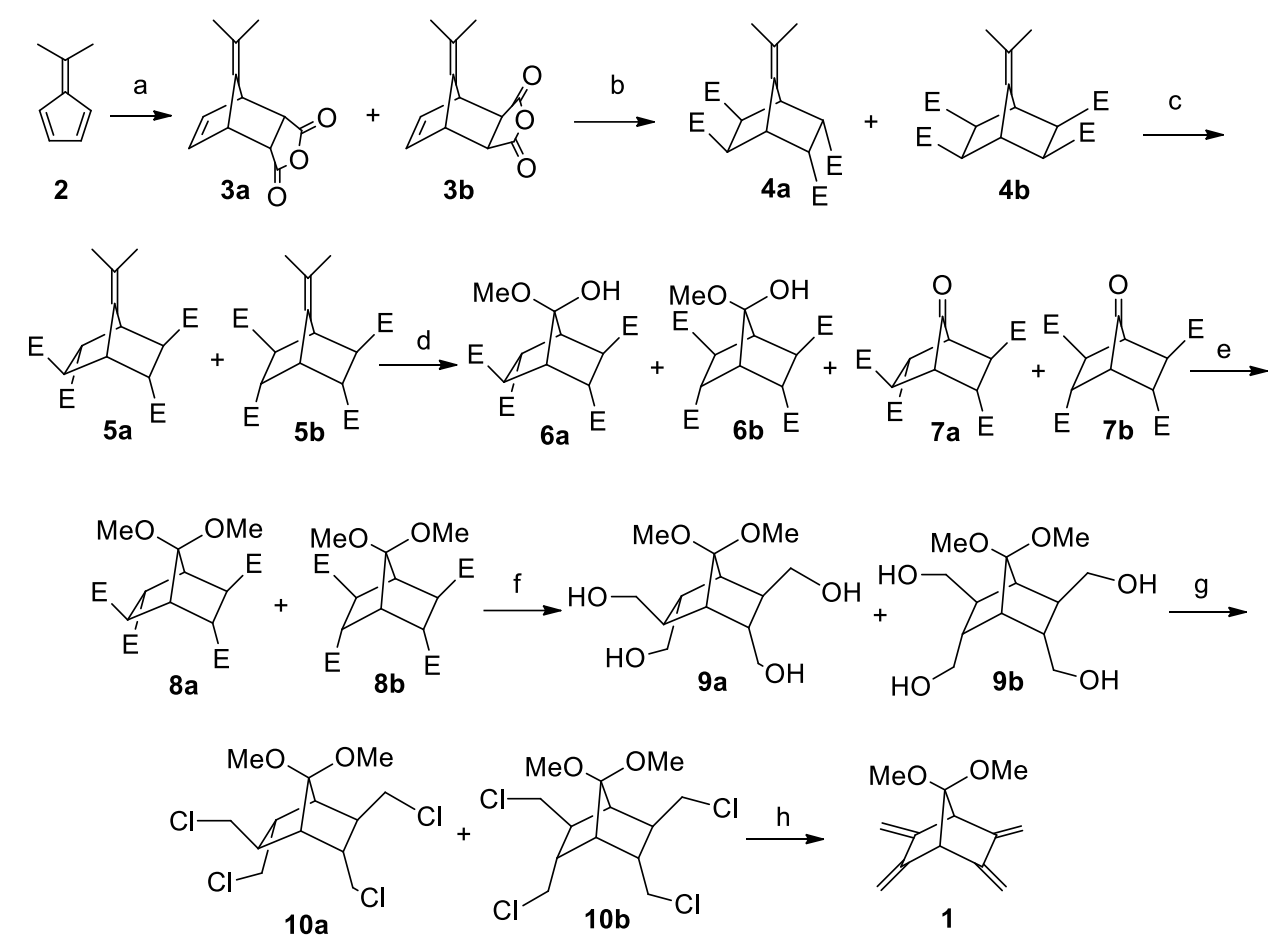

Scheme 2. Synthesis of 1. a) maleic anhydride, DCM; 86\% b) $\mathrm{Pd} / \mathrm{C}, \mathrm{CuCl} 2, \mathrm{CO}, \mathrm{MeOH} ; 74 \%$ c) $\mathrm{K}_{2} \mathrm{CO}_{3}, \mathrm{MeOH}$; $88 \%$ d) $\mathrm{O}_{3}, \mathrm{Me}_{2} \mathrm{~S}, \mathrm{DCM}-\mathrm{MeOH}$; e) $\mathrm{HC}(\mathrm{OMe})_{3}$, APTS, $\mathrm{MeOH}$; $82 \%$ for two steps $\mathrm{f}$ ) $\mathrm{LiAlH}_{4}, \mathrm{THF}$; $94 \%$ g) Cl2, PPh3, imidazole, DCM-ACN-pyridine; 68\% g) t-BuOK, DMF; $61 \%$.

Diels-Alder addition between 6,6-dimethylfulvene 2 [26] and maleic anhydride gives a ca 1:1 mixture of endo- and exo-isomers $\mathbf{3 a}$ and $\mathbf{3 b}$ in around $90 \%$ yield.[27-30] The next step is a palladium catalysed carboxylation according to Stille.[31] In contrast with Roth[23] who only explored the addition on the endo-isomer $\mathbf{3 a}$, we obtained the mixture of isomers $\mathbf{4 a}$ and $\mathbf{4 b}$ (yield $71-74 \%$ ) by carboxylation of the mixture of isomers $\mathbf{3 a}$ and $\mathbf{3 b}$ with a higher palladium loading $(2 \%)$ and a longer reaction time $(48 \mathrm{~h})$. The following step is the ozonolysis of the double bond to form the carbonyl bridge. For the isomer 4a, which is less sterically crowded, the ozonolysis gives a mixture of hemiacetal $\mathbf{6 c}$ and ketone $\mathbf{7 c}$ (scheme 3 ). Then the mixture is protected as the ketal $\mathbf{8 c}$ in $89 \%$ overall yield.

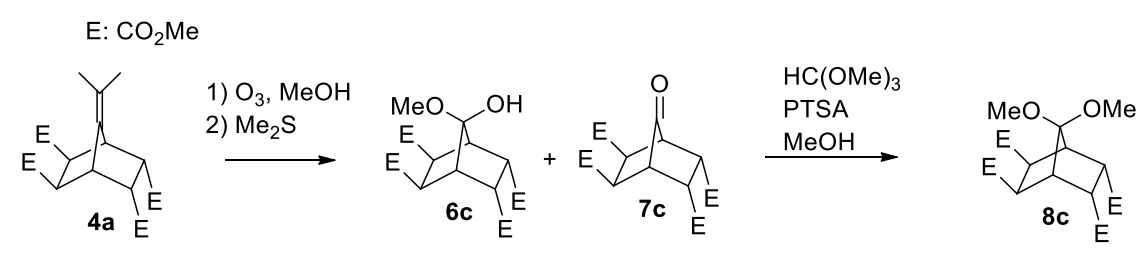

Scheme 3. Ozonolysis of 4 a followed by protection of the bridging ketone.

As this reaction does not proceed well with the compound $\mathbf{4 b}$ due to steric hindrance,[32] with, in particular, the formation of epoxides, we prepare $\mathbf{5 a} / \mathbf{b}$ by isomerisation in basic medium in $88 \%$ yield. Then ozonolysis in a 1:1 mixture of dichloromethane and methanol at $70^{\circ} \mathrm{C}$, followed by quenching by dimethylsulfide gave a mixture of hemiacetal $\mathbf{6 a} / \mathbf{b}$ and carbonyl-bridged $\mathbf{7 a} / \mathbf{b}$ in the ratio $4: 1$. At larger scale, this ozonolysis can be performed at 
high concentration (218 mmol.L-1). The mixture of $\mathbf{6 a} / \mathbf{b}$ and $\mathbf{7 a} / \mathbf{b}$ is then treated with trimethylorthoformate and a catalytic amount of PTSA in methanol to obtain the ketal $\mathbf{8 a} / \mathbf{b}$ in 82-89\% yield for the two steps. Then reduction of the four ester groups by $\mathrm{LiAlH}_{4}$ in $\mathrm{THF}$ gives the mixture of tetraol isomers $\mathbf{9 a} / \mathbf{b}$ at $94 \%$ yield. The poorly soluble tetraols are then

chlorinated by gaseous chlorine in a solution of triphenylphosphine in dichloromethane/acetonitrile/pyridine to give the mixture of isomers $\mathbf{1 0 a} / \mathbf{b}$ in $68 \%$ yield. Attempts to carry out this step by other procedures to avoid gaseous chlorine $\left(\mathrm{SOCl}_{2}, \mathrm{CCl}_{4}\right.$ $\mathrm{PPh}_{3}$, mesylation, tosylation) led to intractable complex mixtures. The reported quadruple dehydrochlorination of 10a was carried out in scale of few hundred milligrams, in very harsh reaction conditions (heating with $\mathrm{CsF}$ at $210^{\circ} \mathrm{C}$ in HMPA)[25] and moderate yield (78\%). In our hands, this protocol led only to a complex mixture of inseparable products. As it can be hardly envisaged to apply this method for large scale preparation in carcinogenic HMPA, we developed a new alternative protocol using mild reaction conditions which can be easily conducted in large scale. After several attempts we found to be most effective base potassium tert-butoxide in anhydrous $\mathrm{DMF}$ at $50^{\circ} \mathrm{C}$ which provide the target product $\mathbf{1}$ in $61 \%$ yields as a stable colourless crystalline compound.

\section{X-ray structure}

The molecular structure of $\mathbf{1}$ was confirmed by a single-crystal X-ray crystallographic analysis (CCDC 1911789, Figure 1).

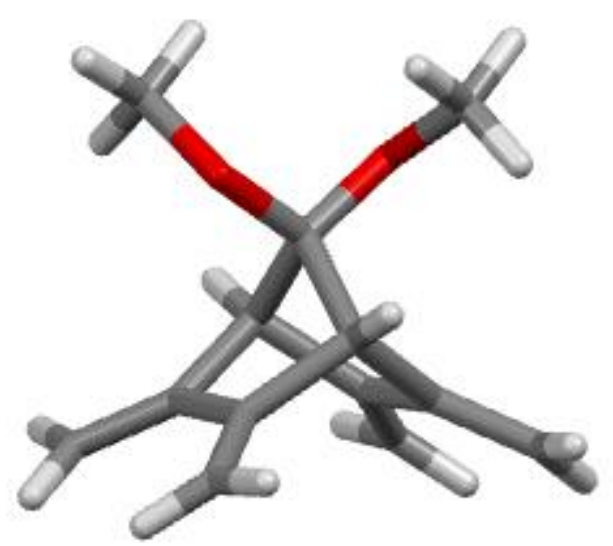

Figure 1. ORTEP plot of 1 (probability ellipsoid: 50\%)

The molecule crystallizes in the monoclinic space group P21 with 2 molecules per unit cell. The dihedral angle between the planes C8-C3-C4-C9 and C11-C7-C6-C10 containing the dienes is $112^{\circ}$. 


\section{Application to the preparation of pentacene}

As an example of the use of $\mathbf{1}$ in the straightforward preparation of long acenes, 6,13-dihydro6,13-methanopentacen-15-one (12) can be prepared in 2 steps starting from 1 (scheme 4), following the route described in scheme 1. Compound 12 has been described as a new type of soluble pentacene precursor for organic thin-film transistors.[4, 33] Pentacene films were obtained by spin-coating of stable and soluble 12, evaporation of the solvent and decarbonylation. This $\mathrm{CO}$ extrusion at $150^{\circ} \mathrm{C}$ gave films of pentacene of high quality stable up to $350^{\circ} \mathrm{C}$.

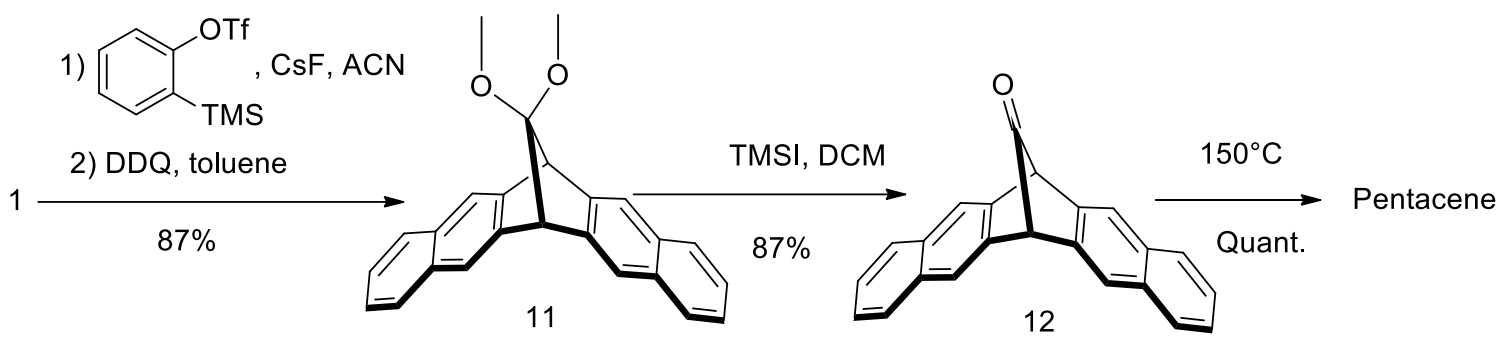

Scheme 4. Preparation of pentacene from 1

Diels-Alder addition of $\mathbf{1}$ and benzyne, generated in situ by the action of CsF on 2(trimethylsilyl)phenyl trifluoromethanesulfonate in acetonitrile, gives, after oxidation by DDQ, 15,15-dimethoxy-6,13-dihydro-6,13-methanopentacene (11) in 87\% yield. Then the ketone is deprotected by trimethylsilyl iodide to give 6,13-dihydro-6,13-methanopentacen-15one (12) in $87 \%$ yield.

\section{Conclusions}

To sum-up, we present here the synthesis of the tetraene 7,7-dimethoxy-2,3,5,6tetramethylenebicyclo[2.2.1] heptane (1) from 6,6-dimethylfulvene $\mathbf{2}$ in 8 steps, with a total yield of ca $17 \%$, at the tens of grams scale. 1 allows the preparation of stable and soluble protected acenes by Diels-Alder [4+2] addition. As an example, in the case of pentacene, the deprotection of the bridging carbonyl group, followed by a thermal or photochemical decarbonylation in the solid state gives an access to pure pentacene in $76 \%$ yield from 1 .

\section{Experimental section}

All reagents and solvents were obtained from commercial sources and used as received. Methanol was dried over molecular sieves $(3 \AA)$. Other anhydrous solvents were purchased in anhydrous quality and used as received. Ozone was generated from a C-Lasky series Ozone Generator C-L010-DT / C-L010-DS (AirTree Ozone Technology Co.). TLC was performed on silica gel 60 F254-coated aluminium sheets (Merck) and spots were detected by the solution of $\mathrm{Ce}\left(\mathrm{SO}_{4}\right)_{2} \cdot 4 \mathrm{H}_{2} \mathrm{O}(1 \%)$ and $\mathrm{H}_{3} \mathrm{P}\left(\mathrm{Mo}_{3} \mathrm{O}_{10}\right)_{4}(2 \%)$ in sulfuric acid (10\%). Flash chromatography was performed on silica gel $60(0.040-0.063 \mathrm{~mm}$, Fluka). 1H NMR spectra were measured on a Bruker $\mathrm{AC} 300$ at $300 \mathrm{MHz}$ at $25^{\circ} \mathrm{C}$, in $\mathrm{CDCl}_{3}, \mathrm{DMSO}-\mathrm{d} 6$ and tetrachloroethane-d 2 as indicated in $5 \mathrm{~mm}$ PFG probe. For standardisation of $1 \mathrm{H} \mathrm{NMR}$ 
spectra the internal signal of TMS $\left(\delta 0.0, \mathrm{CDCl}_{3}\right)$ or residual signals of solvents $(\delta 7.26$ for $\mathrm{CDCl} 3, \delta 2.5$ for DMSO-d6, 6.0 for TCE-d2) were used. In the case of $13 \mathrm{C}$ spectra the residual signals of solvents ( $\delta 77.00$ for $\mathrm{CDCl} 3,73.78$ for DMSO-d6) were used. The chemical shifts are given in $\delta$-scale, the coupling constants $\mathrm{J}$ are given in $\mathrm{Hz}$. All shifts were reported in ppm and processed with MestreNova (Mestrelabs). The ESI mass spectra were recorded using ZQ micromass mass spectrometer (Waters) equipped with an ESCi multimode ion source and controlled by MassLynx software. Alternatively, the low resolution ESI mass spectra were recorded using a quadrupole orthogonal acceleration time-of-flight tandem mass spectrometer (Q-Tof micro, Waters) and high resolution ESI mass spectra using a hybrid FT mass spectrometer combining a linear ion trap MS and the Orbitrap mass analyzer (LTQ Orbitrap XL, Thermo Fisher Scientific). The conditions were optimised for suitable ionisation in the ESI Orbitrap source (sheath gas flow rate 35 a.u., aux gas flow rate 10 a.u. of nitrogen, source voltage $4.3 \mathrm{kV}$, capillary voltage $40 \mathrm{~V}$, capillary temperature $275^{\circ} \mathrm{C}$, tube lens voltage $155 \mathrm{~V})$. The samples were dissolved in methanol and applied by direct injection. As a mobile phase $80 \%$ methanol was used (flow rate $100 \mu \mathrm{l} / \mathrm{min}$ ). Crystallographic data were collected on Bruker D8 VENTURE Kappa Duo PHOTON100 by I $\mu \mathrm{S}$ micro-focus sealed tube MoKa radiation $(\lambda=0.71073 \AA$ ) at a temperature of $120(2) \mathrm{K}$. The structures were solved by direct methods (XP[34]) and refined by full matrix least squares based on F2 (SHELXL20182).[35] The hydrogen atoms on carbon were fixed into idealized positions (riding model) and assigned temperature factors either $\operatorname{Hiso}(\mathrm{H})=1.2 \mathrm{Ueq}$ (pivot atom). Supplementary crystallographic data for this paper can be obtained free of charge from The Cambridge Crystallographic Centre via www.ccdc.cam.ac.uk/data_request/cif) under the reference: CCDC 1911789.

\section{Syntheses}

\section{5-(propan-2-ylidene)cyclopenta-1,3-diene (2)}

Cyclopentadiene was prepared from its dimer by heating at $220{ }^{\circ} \mathrm{C}$ under argon in a distillation apparatus. Cyclopentadiene was collected in a round-bottom flask which was cooled to $-20^{\circ} \mathrm{C}$ using dry ice/ ethanol cooling bath. The freshly distilled cyclopentadiene (96.3 $\mathrm{g}, 1.46 \mathrm{~mol})$ was dissolved under argon in a solution of acetone $(97.1 \mathrm{~mL}, 1.31 \mathrm{~mol}, 0.9$ equiv.) in methanol $(800 \mathrm{~mL})$ keeping the temperature of reaction mixture below $-10^{\circ} \mathrm{C}$. Then pyrrolidine (144 mL, $1.75 \mathrm{~mol}, 1.2$ equiv.) was added dropwise and the yellow reaction mixture was warmed to room temperature over $1 \mathrm{~h}$. Then acetic acid $(117 \mathrm{~mL}, 2.04 \mathrm{~mol}, 1.4$ equiv.) was slowly added. After $10 \mathrm{~min}$. the reaction mixture was poured in cold water (2 L) and extracted twice with diethyl ether. Combined organic layers were dried over anhydrous magnesium sulfate and all volatiles were removed in vacuum. The product 1 (139 g, quant.) was obtained as a yellow oil and used in next step without any further purification. 1H NMR and 13C NMR were in agreement with the published data for 2 prepared at the $5 \mathrm{mmol}$ scale.[36,37]

$(1 S, 2 R, 6 S, 7 R)(3 a)$ and $(1 S, 2 S, 6 R, 7 R)-10$-iso-Propylidene-4-oxatricyclo[5.2.1.02.6]dec-8ene-3,5-dione (3b) 
5-(Propan-2-ylidene)cyclopenta-1,3-diene 2 (139 g, 1.31 mol) was dissolved in dichloromethane $(600 \mathrm{~mL})$ under argon and then maleic anhydride $(135 \mathrm{~g}, 1.38 \mathrm{~mol}, 1.05$ equiv.) was added as a solid. The deep yellow reaction mixture was stirred at room temperature for $16 \mathrm{~h}$. Then the reaction mixture was concentrated in vacuum and the semisolid residue was treated with diethylether to get white crystalline compound as a single exo-isomer $\mathbf{3 b}(80 \mathrm{~g})$. The mother liquor was evaporated and the residue was filtered through a short plug of silica gel (eluent dichloromethane) to get a mixture of endo $\mathbf{3 a}$ and exo $\mathbf{3 b}$ isomers contaminated with maleic anhydride. This mixture was recrystallized from diethyl ether / hexane to get a portion of mixture of both isomers (123 g, enriched with endo 3a). The mother liquor was evaporated and the solid was finally purified by column chromatography on silica gel (hexane/diethyl ether 3:1) to remove the remaining maleic anhydride and get the final portion ( $27 \mathrm{~g}$ ) of mixture of both isomers $\mathbf{3 a}$ and $\mathbf{3 b}$. Total yield of both isomers is $86 \%$ $(230 \mathrm{~g}) .1 \mathrm{H}$ and $13 \mathrm{C} \mathrm{NMR}$ of $\mathbf{3 a} / \mathbf{b}$ were in agreement with the published data (synthesis at the $100 \mathrm{mmol}$ scale).[30]

TLC (hexane/diethyl ether 3:1): for $\mathbf{3 a} \mathrm{Rf}=0.4$, for $\mathbf{3 b} \mathrm{Rf}=0.3$

1H NMR (300 MHz, $\mathrm{CDCl}_{3}$ ), isomer 3a: $6.44(\mathrm{t}, \mathrm{J}=2.0 \mathrm{~Hz}, 2 \mathrm{H}), 3.95-3.90(\mathrm{~m}, 2 \mathrm{H}), 3.52$ $(\mathrm{dd}, \mathrm{J}=3.0,1.7 \mathrm{~Hz}, 2 \mathrm{H}), 1.58$ (s, 6H).

1H NMR (300 MHz, $\mathrm{CDCl}_{3}$ ), isomer 3b: 6.46-6.42 (m, 3H), 3.92 (ddt, J = 3.6, 3.0, $1.9 \mathrm{~Hz}$, $1 \mathrm{H}), 3.89-3.85(\mathrm{~m}, 2 \mathrm{H}), 3.52(\mathrm{dd}, \mathrm{J}=3.1,1.7 \mathrm{~Hz}, 1 \mathrm{H}), 3.04(\mathrm{~s}, 2 \mathrm{H}), 1.59$ (s, 6H), $1.58(\mathrm{~s}$, $2 \mathrm{H})$.

$(1 R, 2 S, 3 R, 4 S, 5 R, 6 S)$-tetramethyl

7-(propan-2-ylidene)bicyclo[2.2.1]heptane-2,3,5,6tetracarboxylate (4a) and (1r,2R,3S,4r,5R,6S)-tetramethyl 7-(propan-2ylidene)bicyclo[2.2.1]heptane-2,3,5,6-tetracarboxylate (4b)

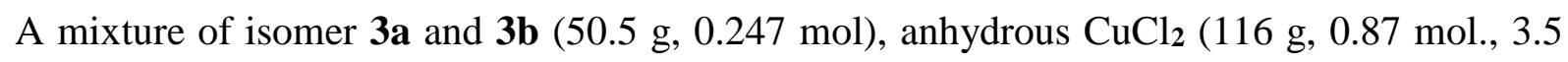
equiv.) and 10\% $\mathrm{Pd} / \mathrm{C}(6.42 \mathrm{~g}, 4.94 \mathrm{mmol}, 2 \mathrm{~mol}$. \%) were placed in an autoclave under argon. Then anhydrous methanol $(500 \mathrm{~mL})$ was added and the reaction mixture was bubbled with argon for $10 \mathrm{~min}$. Then the reaction mixture was pressurized with carbon monoxide (2-5 atm.) and stirred at room temperature for $48 \mathrm{~h}$. The solvent was removed in vacuum and the residue was diluted with dichloromethane and neutralized with saturated sodium hydrogen carbonate solution. This mixed organic-water phase was filtered over a Celite to remove all insoluble inorganics. The filtered solids were washed thoroughly with methanol and dichloromethane. The organic phase was separated and the water phase was extracted with dichloromethane. All combined organic portions were dried over anhydrous magnesium sulfate and evaporated in vacuum. The residue was adsorbed on short plug of silica gel and washed with hexane/EtOAc 20:1 to remove all impurities. Finally, the product was eluted with mixture of dichloromethane/ EtOAc 1:1. Rotoevaporation gave an oily mixture of two isomers $\mathbf{4 a}$ and $\mathbf{4 b}(67.4 \mathrm{~g}, 74 \%)$. 1H NMR of $\mathbf{4 a} / \mathbf{4 b}$ and 13C NMR of $\mathbf{4 b}$ were in agreement with the published data obtained in the $15 \mathrm{~g}$ scale.[38,39] For the analytical purposes, 
compound 4a and $\mathbf{4 b}$ were resolved by column chromatography on silice gel (eluent hexane/EtOAc 2:1).

TLC (hexane/EtOAc 2:1): for $\mathbf{4 a} \mathrm{Rf}=0.4$, for $\mathbf{4 b} \mathrm{Rf}=0.3$.

1H NMR (300 MHz, $\mathrm{CDCl}_{3}$ ), isomer 4a: $3.66(\mathrm{~s}, 6 \mathrm{H}), 3.59$ (s, 6H), $3.42(\mathrm{~s}, 2 \mathrm{H}), 3.26$ (dd, J = 2.6, $1.8 \mathrm{~Hz}, 2 \mathrm{H}), 3.05(\mathrm{dd}, \mathrm{J}=2.6,1.8 \mathrm{~Hz}, 2 \mathrm{H}), 1.70$ (s, 6H).

13C NMR (75 MHz, $\mathrm{CDCl}_{3}$ ), isomer 4a: 20.79, 42.79, 44.50, 45.43, 51.76, 51.90, 121.86, $135.18,172.15,172.89$.

ESI MS, isomer 4a: $391([\mathrm{M}+\mathrm{Na}]+)$.

HR ESI MS, isomer 4a: calcd for $\mathrm{C}_{18} \mathrm{H}_{24} \mathrm{O}_{8} \mathrm{Na} 391.13634$; found 391.13600.

1H NMR (300 MHz, $\mathrm{CDCl}_{3}$ ), isomer 4b: $\delta 3.7(\mathrm{~s}, 12 \mathrm{H}), 3.4(\mathrm{~s}, 2 \mathrm{H}), 2.8(\mathrm{~s}, 4 \mathrm{H}), 1.7(\mathrm{~s}, 6 \mathrm{H})$.

13C NMR (75 MHz, $\mathrm{CDCl}_{3}$ ), isomer 4b: 20.93, 42.82, 49.29, 51.95, 124.89, 133.19, 172.03.

ESI MS, isomer 4b: $391([\mathrm{M}+\mathrm{Na}]+)$.

HR ESI MS, isomer 4b: calcd for $\mathrm{C}_{18} \mathrm{H}_{24} \mathrm{O}_{8} \mathrm{Na}$ 391.13634; found 391.13581.

\section{Tetramethyl}

\section{tetracarboxylate $(8 \mathrm{c})$}

In a round-bottom flask was prepared solution of $\mathbf{4 a}(511 \mathrm{mg}, 1.4 \mathrm{mmol}, 1 \mathrm{eq}$.$) in a mixture of$ dichloromethane $(14 \mathrm{~mL})$ and methanol $(14 \mathrm{~mL})$ was cooled to $-70{ }^{\circ} \mathrm{C}$ and bubbled with ozone $(2 \mathrm{~L} / \mathrm{min})$ until the colour of the reaction mixture became light blue $(3 \mathrm{~h})$. The reaction mixture was bubbled with air for $10 \mathrm{~min}$. to remove excess ozone. Dimethyl sulfide $(0.15 \mathrm{~mL}$, $2 \mathrm{mmol}, 1.4$ eq.) was added at $-70{ }^{\circ} \mathrm{C}$ and the mixture was left to warm to room temperature overnight (ca 17h). All volatiles were removed in vacuo to afford a mixture of hemiacetal $\mathbf{6 c}$ and ketone $7 \mathbf{c}$ in the ratio 4:1 in a form of sticky oil. The well-dried mixture of $\mathbf{6 c}$ and $7 \mathbf{c}$ was dissolved in a mixture of absolute methanol $(20 \mathrm{~mL})$ and triethyl orthoformate $(15 \mathrm{~mL})$. To this p-toluenesulfonic acid $\left(50 \mathrm{mg}, 0.2 \mathrm{mmol}\right.$ ) was added and the solution heated at $64{ }^{\circ} \mathrm{C}$ for 3-5 days. The conversion of reaction was monitored by NMR. When the reaction was completed, all volatiles were evaporated. The residue was diluted with dichloromethane then overlaid with saturated sodium hydrogen carbonate (aq solution) and extracted with dichloromethane. The organic layers were gathered and dried over anhydrous magnesium sulfate. After evaporation the white solid was poured into diethylether and sonicated for 5 min. The product $8 \mathbf{c}$ (480 mg, $1.23 \mathrm{mmol}, 89 \%)$ was filtered as a white solid.

1H NMR (300 MHz, $\left.\mathrm{CDCl}_{3}\right): 3.68(\mathrm{~s}, 6 \mathrm{H}), 3.67(\mathrm{~s}, 6 \mathrm{H}), 3.43(\mathrm{~s}, 2 \mathrm{H}), 3.36(\mathrm{dd}, \mathrm{J}=2.6,1.7$ $\mathrm{Hz}, 2 \mathrm{H}), 3.31$ (s, 3H), 3.28 (s, 3H), 2.92 (dd, J = 2.5, $1.7 \mathrm{~Hz}, 2 \mathrm{H})$.

13C NMR (75 MHz, $\left.\mathrm{CDCl}_{3}\right)$ : 43.13, 43.79, 44.58, 51.10, 51.57, 51.76, 51.97, 112.09, 172.23, 172.40 . 
CI MS: $388([\mathrm{M}]+)$.

HR CI MS: calcd for $\mathrm{C}_{13} \mathrm{H}_{24} \mathrm{O}_{10} 388.1369$; found 388.1357

(1S,2R,3R,4S,5R,6R)-tetramethyl 7-(propan-2-ylidene)bicyclo[2.2.1]heptane-2,3,5,6tetracarboxylate (5a) and (1r,2R,3R,4s,5S,6S)-tetramethyl 7-(propan-2ylidene)bicyclo[2.2.1]heptane-2,3,5,6-tetracarboxylate $(5 \mathrm{~b})$

To a solution of $\mathbf{4 a}$ and $\mathbf{4 b}(67.4 \mathrm{~g}, 0.183 \mathrm{~mol})$ in absolute methanol $(500 \mathrm{~mL})$ was added in one portion anhydrous potassium carbonate $(22.8 \mathrm{~g}, 0.165 \mathrm{~mol}, 0.9$ equiv.) under argon. Then the heterogeneous reaction mixture was stirred at room temperature for $16 \mathrm{~h}$. The reaction mixture was concentrated on a rotoevaporator, then diluted with aqueous solution of ammonium chloride and extracted with dichloromethane. All combined organic portions were dried over anhydrous magnesium sulfate and evaporated in vacuum. The residue was filtered through a short plug of silica gel (eluent dichloromethane/EtOAc 1:1) to get a mixture of $\mathbf{5 a}$ and $\mathbf{5 b}$ isomers (in ratio 5:1) as white solid (59.1 g, $88 \%$ ). 1H NMR and 13C NMR of 5a were in agreement with the published data obtained at the $15 \mathrm{~g}$ scale.[38,39]

1H NMR (300 MHz, $\left.\mathrm{CDCl}_{3}\right)$, isomer 5a: $3.8(\mathrm{~s}, 6 \mathrm{H}), 3.7(\mathrm{~s}, 6 \mathrm{H}), 3.4(\mathrm{~d}, \mathrm{~J}=4.8 \mathrm{~Hz}, 2 \mathrm{H}), 3.2$ $(\mathrm{t}, \mathrm{J}=5.0 \mathrm{~Hz}, 2 \mathrm{H}), 3(\mathrm{~d}, \mathrm{~J}=5.6 \mathrm{~Hz}, 2 \mathrm{H}), 1.6(\mathrm{~s}, 6 \mathrm{H})$.

1H NMR (300 MHz, $\mathrm{CDCl}_{3}$ ), isomer 5b: 1.55 (s, 3H), 1.66 (s, 3H), 3.04 (bs, 1H), 3.06 (bs, $1 \mathrm{H}), 3.16(\mathrm{~d}, \mathrm{~J}=4.2 \mathrm{~Hz}, 1 \mathrm{H}), 3.18(\mathrm{~d}, \mathrm{~J}=4.3 \mathrm{~Hz}, 1 \mathrm{H}), 3.40$ (bs, $1 \mathrm{H}), 3.49$ (td, J = 4.1, $1.5 \mathrm{~Hz}$, $1 \mathrm{H}), 3.63(\mathrm{~s}, 6 \mathrm{H}), 3.67(\mathrm{~s}, 6 \mathrm{H})$.

13C NMR (75 MHz, $\mathrm{CDCl}_{3}$ ), isomer 5b: 20.18, 20.62, 42.87, 44.71, 46.51, 48.22, 52.06, 52.34, 120.97, 136.07, 172.49, 173.49 .

ESI MS, isomer 5b: $391([\mathrm{M}+\mathrm{Na}]+)$.

HR ESI MS, isomer 5b: calcd for $\mathrm{C}_{18} \mathrm{H}_{24} \mathrm{O}_{8} \mathrm{Na} 391.13634$; found 391.13602 .

$(1 S, 2 R, 3 R, 4 S, 5 R, 6 R)$-tetramethyl

tetracarboxylate $\quad(8 \mathrm{a}) \quad$ and $\quad(1 \mathrm{r}, 2 \mathrm{R}, 3 \mathrm{R}, 4 \mathrm{~s}, 5 \mathrm{~S}, 6 \mathrm{~S})$-tetramethyl 7,7-

7,7-dimethoxybicyclo[2.2.1]heptane-2,3,5,6- dimethoxybicyclo[2.2.1] heptane-2,3,5,6-tetracarboxylate $(8 \mathrm{~b})$

A solution of $\mathbf{5 a} / \mathbf{5 b}(48.4 \mathrm{~g}, 0.131 \mathrm{~mol})$ in an anhydrous mixture of dichloromethane (300 $\mathrm{mL}$ ) and methanol $(300 \mathrm{~mL})$ was cooled to $-70^{\circ} \mathrm{C}$ and bubbled with ozone $(2 \mathrm{~L} / \mathrm{min})$ until the colour of the reaction mixture became light blue $(3 \mathrm{~h})$. The reaction mixture was bubbled with nitrogen for $10 \mathrm{~min}$. to remove excess of ozone. Dimethyl sulfide $(13.5 \mathrm{~mL}, 0.183 \mathrm{~mol}, 1.4$ equiv.) was added at $-70{ }^{\circ} \mathrm{C}$ and the mixture was left to warm to room temperature overnight. All volatiles were removed in vacuum to afford a mixture of hemiacetal $\mathbf{6 a} / \mathbf{6 b}$ and ketone $\mathbf{6 a} / \mathbf{b}$ in the ratio $4: 1$ in a form of sticky oil. The well-dried mixture of $\mathbf{6 a} / \mathbf{b}$ and $\mathbf{7 c / d}$ was dissolved in a mixture of anhydrous methanol $(100 \mathrm{~mL})$ and trimethyl orthoformate $(100 \mathrm{~mL})$. To this solution was added p-toluenesulfonic acid (2.49 g, $13.1 \mathrm{mmol}, 0.1$ equiv.) and the reaction mixture was heated at $60^{\circ} \mathrm{C}$ for $24 \mathrm{~h}$ under argon. All volatiles were removed in vacuum and the residue was diluted with dichloromethane then overlaid with saturated 
sodium hydrogen carbonate (aq. solution) and extracted with dichloromethane. All combined organic portions were dried over anhydrous magnesium sulfate. After evaporation the semisolid residue was crystallised from a mixture of hexane/diethyl ether 1:2 to get first portion of product $(31.5 \mathrm{~g})$ as a crystalline solid. The mother liquor was evaporated and the residue was adsorbed on short plug of silica gel and washed with hexane/EtOAc 20:1 to remove all impurities. Finally, the product was eluted with mixture of dichloromethane/ EtOAc 1:1. After evaporation, a second portion of $\mathbf{8 a} / \mathbf{b}(10.1 \mathrm{~g})$ was obtained as a crystalline solid. The total yield was $41.6 \mathrm{~g}(82 \%)$. 1H NMR of $\mathbf{8 a}$ are in agreement with published data.

1H NMR (300 MHz, $\left.\mathrm{CDCl}_{3}\right): 3.75(\mathrm{~s}, 6 \mathrm{H}), 3.70(\mathrm{~s}, 6 \mathrm{H}), 3.55-3.49(\mathrm{~m}, 2 \mathrm{H}), 3.17(\mathrm{~s}, 6 \mathrm{H})$, $3.08(\mathrm{~d}, \mathrm{~J}=4.8 \mathrm{~Hz}, 2 \mathrm{H}), 2.88(\mathrm{~d}, \mathrm{~J}=5.7 \mathrm{~Hz}, 2 \mathrm{H})$.

13C NMR (75 MHz, $\left.\mathrm{CDCl}_{3}\right): 43.40,45.31,45.40,50.68,52.37,52.46,112.76,172.75$, 173.11 .

ESI MS: $411([\mathrm{M}+\mathrm{Na}]+)$.

HR ESI MS: calcd for $\mathrm{C}_{17} \mathrm{H}_{24} \mathrm{O}_{10} \mathrm{Na}$ 411.12617; found 411.12627.

((1R,2S,3S,4R,5S,6S)-7,7-dimethoxybicyclo[2.2.1]heptane-2,3,5,6-tetrayl)tetramethanol

(9a) and $((1 \mathrm{r}, 2 \mathrm{R}, 3 \mathrm{R}, 4 \mathrm{~s}, 5 \mathrm{~S}, 6 \mathrm{~S})-7,7-d i m e t h o x y b i c y c l o[2.2 .1]$ heptane-2,3,5,6tetrayl)tetramethanol $(9 \mathrm{~b})$

A well-dried round bottom flask equipped with reflux condenser was loaded with lithium aluminum hydride (15.4 g, 0.405 mol, 5 equiv.) and purged with argon. Freshly distilled anhydrous tetrahydrofuran $(500 \mathrm{~mL})$ was added and the mixture was cooled to $-70{ }^{\circ} \mathrm{C}$. To this very viscous heterogeneous solution was added dropwise by cannula a solution of $\mathbf{8 a} / \mathbf{b}(31.5$ $\mathrm{g}, 81.1 \mathrm{mmol})$ in dry tetrahydrofuran $(200 \mathrm{~mL})$. The reaction mixture was allowed to warm up to room temperature over a period of $5 \mathrm{~h}$. The reaction mixture was then heated at $70{ }^{\circ} \mathrm{C}$ for $16 \mathrm{~h}$. Then the reaction mixture was cooled back to room temperature and quenched with minimum amount of saturated aqueous solution of magnesium sulfate. The whole reaction mixture was adsorbed on silica gel and the product was extracted by continuous extraction using THF as an eluent. After evaporation of the solvent, the product $\mathbf{9 a} / \mathbf{b}(21 \mathrm{~g}, 94 \%)$ was obtained as white crystalline compound. 1H NMR of 9a is in agreement with the published data.[25]

1H NMR (300 MHz, DMSO): 1.44 (dd, J = 7.2, 7.2 Hz, 2H), 1.75-1.74(m, 2H), 1.96 (d, J = $3.3 \mathrm{~Hz}, 2 \mathrm{H}), 3.10$ (s, 6H), $3.34-3.49$ (m, 8H), $4.40-4.46(\mathrm{~m}, 4 \mathrm{H})$.

13C NMR (75 MHz, DMSO): 40.59, 41.83, 44.45, 48.99, 61.12, 64.38, 113.54.

ESI MS: $299([\mathrm{M}+\mathrm{Na}]+)$

HR ESI MS: calcd for $\mathrm{C}_{13} \mathrm{H}_{24} \mathrm{O}_{6} \mathrm{Na} 299.14651$; found 299.14630 
(1S,2R,3R,4S,5R,6R)-2,3,5,6-tetrakis(chloromethyl)-7,7-dimethoxybicyclo[2.2.1]heptane (10a) and dimethoxybicyclo[2.2.1]heptane (10b)

(1r,2R,3R,4s,5S,6S)-2,3,5,6-tetrakis(chloromethyl)-7,7-

Into a cooled $\left(0^{\circ} \mathrm{C}\right)$ solution of triphenylphosphine $(91.1 \mathrm{~g}, 0.347 \mathrm{~mol}, 8$ equiv. $)$ in dichloromethane $(400 \mathrm{~mL})$ was bubbled gaseous chlorine. When triphenylphosphine was consumed (the colour of the reaction turned to yellow), argon was bubbled in the reaction mixture to remove excess of chlorine. Then this solution of chlorophosphonium salt was added dropwise (by cannula) to a solution of imidazole (47.3 g, $0.694 \mathrm{~mol}, 16$ equiv.) in a mixture of solvents acetonitrile - pyridine $(200 \mathrm{~mL}: 200 \mathrm{~mL})$ at $0^{\circ} \mathrm{C}$. Then tetraol $\mathbf{9 a} / \mathbf{b}(12 \mathrm{~g}$, $43.4 \mathrm{mmol}$ ) was added portion-wise and the reaction mixture was warmed to room temperature and stirred for $30 \mathrm{~min}$. Then the reaction mixture was heated at $55^{\circ} \mathrm{C}$ for $24 \mathrm{~h}$ under argon. The reaction mixture was diluted with chloroform and extracted several times with $2 \mathrm{M} \mathrm{HCl}$ and finally a saturated aqueous solution of $\mathrm{NaHCO}$. The organic phase was dried with $\mathrm{MgSO}_{4}$ and evaporated. To the solid residue was added diethyl ether and precipitated triphenylphosphinoxide was filtered over a frit. The filtrate was evaporated and the residue was chromatographed on silica gel (hexane:EtOAc 6:1) to get the desired tetrachloro product $\mathbf{1 0 a} / \mathbf{b}(10.4 \mathrm{~g}, 68 \%)$ as a white crystalline compound. 1H NMR of 10a is in agreement with the published data.[25]

1H NMR (300 MHz, $\left.\mathrm{CDCl}_{3}\right): 1.72(\mathrm{td}, \mathrm{J}=7.8,6.5 \mathrm{~Hz}, 2 \mathrm{H}), 2.21-2.30(\mathrm{~m}, 2 \mathrm{H}), 2.32-2.34$ (m, 2H), $3.24(\mathrm{~s}, 6 \mathrm{H}), 3.45(\mathrm{t}, \mathrm{J}=10.8 \mathrm{~Hz}, 2 \mathrm{H}), 3.62-6.38(\mathrm{~m}, 2 \mathrm{H}), 3.743 .86(\mathrm{~m}, 4 \mathrm{H})$.

13C NMR (75 MHz, $\left.\mathrm{CDCl}_{3}\right): 42.53,44.46,45.47,45.96,48.13,50.12,112.82$.

CI MS: $348([\mathrm{M}]+)$.

HR CI MS: calcd for $\mathrm{C}_{13} \mathrm{H}_{20} \mathrm{O}_{2} \mathrm{Cl}_{4}$ 348.0217; found 348.0215

\section{7,7-dimethoxy-2,3,5,6-tetramethylenebicyclo[2.2.1]heptane (1)}

In a well dried Schlenk flask, a solution of potassium tert-butoxide $(16.7 \mathrm{~g}, 0.149 \mathrm{~mol}, 5$ equiv.) in anhydrous DMF $(100 \mathrm{~mL})$ was cooled to $0^{\circ} \mathrm{C}$. To this solution was added dropwise a solution of the tetrachloride 10a/b $(10.4 \mathrm{~g}, 29.7 \mathrm{mmol})$ in anhydrous DMF (20 mL). After the complete addition, the reaction mixture was warmed to room temperature and finally heated at $50^{\circ} \mathrm{C}$ overnight under argon. The reaction mixture was diluted with water and extracted with EtOAc. The combined organic portions were dried over anhydrous $\mathrm{MgSO}_{4}$. The solvents were removed in vacuum and the residue was chromatographed on silica gel (gradient from hexane/dichloromethane 6:1 to 2:1) to get the desired product $\mathbf{1}(3.7 \mathrm{~g}, 61 \%)$ as a white crystalline compound. 1H NMR is in agreement with the published data.[25]

1H NMR (300 MHz, $\left.\mathrm{CDCl}_{3}\right): 3.27$ (s, 6H), 3.47 (s, 2H), $5.01(\mathrm{~s}, 4 \mathrm{H}), 5.30$ (s, 4H).

13C NMR (75 MHz, $\left.\mathrm{CDCl}_{3}\right): 50.90,58.52,103.47,110.85,146.65$.

CI MS: $205([\mathrm{M}+\mathrm{H}]+)$.

HR CI MS: calcd for $\mathrm{C}_{13} \mathrm{H}_{17} \mathrm{O}_{2} 205.1229$; found 205.1230 


\section{5,15-dimethoxy-6,13-dihydro-6,13-methanopentacene (11)}

A well dried Schlenk flask was charged with tetraene 1 (500 mg, $2.45 \mathrm{mmol}, 1$ equiv.) and dry CsF (1.49 g, 9.79 mmol, 4 equiv.) under argon and then anhydrous acetonitrile was added $(50 \mathrm{~mL})$. The reaction mixture was cooled to $0^{\circ} \mathrm{C}$ and then 2-(trimethylsilyl)phenyl trifluoromethanesulfonate $(1.3 \mathrm{~mL}, 5.39 \mathrm{mmol}, 2.2$ equiv.) was added dropwise. The mixture was stirred at room temperature overnight. After evaporation of the solvent, the residue was filtered over short plug of silica gel and flushed with hexane/THF 20:1. Rotoevaporation of the organic solvents gave the crude product which was well dried under vacuum and then dissolved in anhydrous toluene $(40 \mathrm{~mL})$ under argon. This solution was cooled to $0^{\circ} \mathrm{C}$ and DDQ (1.11 g, 4.9 mmol, 2 equiv.) was added in one portion. The reaction mixture was warmed to room temperature and stirred for $3 \mathrm{~h}$. After filtration to remove reduce DDQ, evaporation of solvents gave a residue which was chromatographed on silica gel (hexane/dichloromethane 2:3) to get the product $11(751 \mathrm{mg}, 87 \%)$ as a white crystalline compound.

1H NMR (300 MHz, $\left.\mathrm{CDCl}_{3}\right): 3.22(\mathrm{~s}, 6 \mathrm{H}), 7.35-7.41(\mathrm{~m}, 4 \mathrm{H}), 4.69-7.75(\mathrm{~m}, 8 \mathrm{H})$.

13C NMR (75 MHz, $\left.\mathrm{CDCl}_{3}\right): 51.54,55.32,120.88,125.49,125.99,128.17,133.04,143.91$.

DCI MS: $353([\mathrm{M}+\mathrm{H}]+)$.

HR DCI MS: calcd for $\mathrm{C}_{25} \mathrm{H}_{21} \mathrm{O}_{2}$ 353.1536; found 353.1529.

\section{6,13-dihydro-6,13-methanopentacen-15-one (12)}

In a well-dried Schlenk flask, 11 was dissolved (140 $\mathrm{mg}, 0.4 \mathrm{mmol})$ in anhydrous dichloromethane $(15 \mathrm{~mL})$ under argon. Then trimethylsilyl iodide $(68 \mu \mathrm{L}, 0.48 \mathrm{mmol}, 1.2$ equiv) was added dropwise and reaction mixture was stirred overnight at room temperature. The reaction mixture was then heated at $40^{\circ} \mathrm{C}$ for $1 \mathrm{~h}$, then cooled to room temperature and rotoevaporated. Sonication of the residue in a mixture of solvents (hexane/diethyl ether 4:1) yielded pure product $12(106 \mathrm{mg}, 87 \%)$ as a white powder. $1 \mathrm{H} \mathrm{NMR}$ is in agreement with published data.[33]

1H NMR (300 MHz, [D2] tetrachloroethane): 5.00 (s, 2H), $7.45-7.51$ (m, 4H), $7.80-7.85$ (m, 4H), $7.95(\mathrm{~s}, 4 \mathrm{H})$.

\section{Acknowledgments}

The authors thank Yannick Coppel (LCC-Toulouse) for recording CP-MAS spectra, David Neumeyer (CEMES) for recording TGA spectra. A. J. acknowledges funding from the Foundation EXPERIENTIA and from ERDF/ESF "UOCHB MSCA Mobility" (No. CZ.02.2.69/0.0/0.0/17_050/0008490). This research has been funded by the EraNET Cofund Initiatives QuantERA under the European Union's Horizon 2020 research and innovation programme grant agreement ORQUID and by the ANR-MOST project MQwires. 
Keywords: tetraene $\bullet$ cycloaddition $\bullet$ ozonolysis $\bullet$ protecting group $\bullet$ carboxylation

\section{References}

[1] R. Dorel, A. M. Echavarren, Eur. J. Org. Chem. 2016, 2017, 14-24.

[2] O. T. Dyan, G. I. Borodkin, P. A. Zaikin, Eur. J. Org. Chem. 2019, 2019, 7271-7306.

[3] J. E. Anthony, Chem. Rev. 2006, 106, 5028-5048.

[4] M. Watanabe, K.-Y. Chen, Y. J. Chang, T. J. Chow, Acc. Chem. Res. 2013, 46, 1606-1615.

[5] W. Han, R. K. Kawakami, M. Gmitra, J. Fabian, Nat. Nanotechnol. 2014, 9, 794.

[6] L. Bursi, A. Calzolari, S. Corni, E. Molinari, ACS Photonics 2014, 1, 1049-1058.

[7] J. Krüger, N. Pavliček, J. M. Alonso, D. Pérez, E. Guitián, T. Lehmann, G. Cuniberti, A. Gourdon, G. Meyer, L. Gross, F. Moresco, D. Peña, ACS Nano 2016, 10, 4538-4542.

[8] J. I. Urgel, H. Hayashi, M. Di Giovannantonio, C. A. Pignedoli, S. Mishra, O. Deniz, M. Yamashita, T. Dienel, P. Ruffieux, H. Yamada, R. Fasel, J. Am. Chem. Soc. 2017, 139, 11658-11661.

[9] M. Zugermeier, M. Gruber, M. Schmid, B. P. Klein, L. Ruppenthal, P. Muller, R. Einholz, W. Hieringer, R. Berndt, H. F. Bettinger, J. M. Gottfried, Nanoscale 2017, 9, 12461-12469.

[10] R. Zuzak, R. Dorel, M. Krawiec, B. Such, M. Kolmer, M. Szymonski, A. M. Echavarren, S. Godlewski, ACS Nano 2017, 11, 9321-9329.

[11] R. Zuzak, R. Dorel, M. Kolmer, M. Szymonski, S. Godlewski, A. M. Echavarren, Angew. Chem. Int. Ed. 2018, 57, 10500-10505.

[12] J. Krüger, F. Eisenhut, D. Skidin, T. Lehmann, D. A. Ryndyk, G. Cuniberti, F. García, J. M. Alonso, E. Guitián, D. Pérez, D. Peña, G. Trinquier, J.-P. Malrieu, F. Moresco, C. Joachim, ACS Nano 2018, 12, 8506-8511.

[13] J. Krüger, F. García, F. Eisenhut, D. Skidin, J. M. Alonso, E. Guitián, D. Pérez, G. Cuniberti, F. Moresco, D. Peña, Angew. Chem. Int. Ed. 2017, 56, 11945-11948.

[14] L. Colazzo, M. S. G. Mohammed, R. Dorel, P. Nita, C. García Fernández, P. Abufager, N. Lorente, A. M. Echavarren, D. G. de Oteyza, Chem. Commun. 2018, 54, 10260-10263.

[15] J. I. Urgel, S. Mishra, H. Hayashi, J. Wilhelm, C. A. Pignedoli, M. Di Giovannantonio, R. Widmer, M. Yamashita, N. Hieda, P. Ruffieux, H. Yamada, R. Fasel, Nat. Commun. 2019, 10, DOI 10.1038/s41467-019-08650-y.

[16] C. Tönshoff, H. F. Bettinger, in Polyarenes I (Eds.: J.S. Siegel, Y.-T. Wu), Springer Berlin Heidelberg, Berlin, Heidelberg, 2014, pp. 1-30.

[17] R. Mondal, B. K. Shah, D. C. Neckers, J. Am. Chem. Soc. 2006, 128, 9612-9613.

[18] H. F. Bettinger, R. Mondal, D. C. Neckers, Chem. Commun. 2007, 5209-5211.

[19] R. Mondal, C. Tönshoff, D. Khon, D. C. Neckers, H. F. Bettinger, J. Am. Chem. Soc. 2009, $131,14281-14289$.

[20] C. Tönshoff, H. F. Bettinger, Angew. Chem. Int. Ed. 2010, 49, 4125-4128.

[21] B. Shen, J. Tatchen, E. Sanchez-Garcia, H. F. Bettinger, Angew. Chem. Int. Ed. 2018, 57, 10506-10509.

[22] M. Watanabe, Y. J. Chang, S.-W. Liu, T.-H. Chao, K. Goto, IslamMd. Minarul, C.-H. Yuan, Y.-T. Tao, T. Shinmyozu, T. J. Chow, Nat Chem 2012, 4, 574-578.

[23] A. Jancarik, G. Levet, A. Gourdon, Chem. - Eur. J. 2019, 25, 2366-2374.

[24] R. Einholz, T. Fang, R. Berger, P. Grüninger, A. Früh, T. Chassé, R. F. Fink, H. F. Bettinger, J. Am. Chem. Soc. 2017, 139, 4435-4442.

[25] Roth Wolfgang R., Langer Reinhard, Ebbrecht Thomas, Beitat Arndt, Lennartz Hans-Werner, Chem. Ber. 1991, 124, 2751-2760.

[26] K. J. Stone, R. D. Little, J. Org. Chem. 1984, 49, 1849-1853.

[27] B. Uebersax, M. Neuenschwander, H.-P. Kellerhals, Helv. Chim. Acta 1982, 65, 74-88.

[28] M. S. Erickson, J. M. Cronan, J. G. Garcia, M. L. McLaughlin, J. Org. Chem. 1992, 57, 25042508.

[29] R. B. Woodward, H. Baer, J. Am. Chem. Soc. 1944, 66, 645-649.

[30] C. Reynaud, Y. Fall, M. Feuerstein, H. Doucet, M. Santelli, Tetrahedron 2009, 65, 74407448 .

[31] J. K. Stille, R. Divakaruni, J. Org. Chem. 1979, 44, 3474-3482.

[32] A. Rubello, P. Vogel, G. Chapuis, Helv. Chim. Acta 1987, 70, 1638-1648. 
[33] K.-Y. Chen, H.-H. Hsieh, C.-C. Wu, J.-J. Hwang, T. J. Chow, Chem. Commun. 2007, 10651067.

[34] G. M. Sheldrick, Acta Crystallogr. Sect. Found. Adv. 2015, 71, 3-8.

[35] G. M. Sheldrick, Acta Crystallogr. Sect. C Struct. Chem. 2015, 71, 3-8.

[36] S. Tamke, C.-G. Daniliuc, J. Paradies, Org. Biomol. Chem. 2014, 12, 9139-9144.

[37] N. Coşkun, I. Erden, Tetrahedron 2011, 67, 8607-8614.

[38] L. De Piccioto, P. A. Carrupt, P. Vogel, J. Org. Chem. 1982, 47, 3796-3799.

[39] Rubello Albino, Vogel Pierre, Helv. Chim. Acta 1988, 71, 1268-1280. 